\title{
Telemedicine's Patients and Their Protection: What Does The International Law Offer? (A Perspective From Indonesia)
}

\author{
Melly Aida ${ }^{1}$, Orima Davey ${ }^{2}$ \\ \{aidamel.ma@gmail.com ${ }^{1}$, oridavey23@gmail.com² \\ Faculty of Law University of Lampung, Indonesia ${ }^{12}$
}

\begin{abstract}
The international law has always been one to introduce new things for the sake of human kind's progress. With its uniqueness of connecting through the world, the international law is also available of adjusting the life of humanity. Besides of prioritizing health, education, and welfare, the pressure of globalization has taken us to the front door of a developed globalization, which in this case can be seen from the modern life of technology. Thus, it would a better option for law experts to acknowledge the ways of embracing technology through the crisis matter of all time, health. Telemedicine would be a great example of any hypothesis regarding to balancing health and technology without neglecting the idea of its possibilities to be enhanced in developing countries such as Indonesia. Therefore, it is important to understand the regulation regarding to telemedicine and the provided legal protection for its patients based on the international in order to realize health advancement of Indonesia's citizens evenly. This research could be taken advantage by stakeholders in the health sectors. The method used is normative law research with focus of purpose on fact findings, problem identifications, and problem solution.
\end{abstract}

Keywords: Health Services; Legal Protection; International Law; Telemedicine

\section{Introduction}

Health is a crucial component of human lives and never ceases to be a problem in discussing the international agenda. The development of the era along with the increasing plurality of components of life, caused experts to consider the existence of health care at a new level; through technological involvement. Technology became modern throughout the years and is applied in human lives including in far distance; for an instance, the internet. As many as 15.000 health websites have dominated the society both in managing a healthy lifestyle or merely complaints from an illness. These websites' qualities vary which grew concerns from the medical professions. The process of exchanging health information from a medical profession to a patient that is separated by distance which causes the consultation performed through technology device is known as telemedicine.

Telemedicine allows patients worldwide to complete their health need without experiencing distance that cost finance and money. This health service technique is very potential for patients that live in an isolated area. However, there is an ongoing of using telemedicine universally, especially in terms of the patient's protection. Distance and 
technology in between the medical professions and patients complicates the idea to implement protection for telemedicine's patients that will experience disadvantage in the near future.

Indonesia is a country with 266.795 .00 population and life expectancy at 61.7 years old. Afterwards, in every 1000 population, there are at least 7 deaths which put Indonesia as the 2nd place for the highest morality rate of South East Asia. The high rate of mortality in Indonesia's background is poor health services. Factors that cause poor health services are (1) Citizens in poverty have low health status, (2) Double burden which is the improvement of contagious and not contagious disease, (3) Poor equity, access, and quality of health facilities, (4) Limited resource for medical professions. Based on these issues, telemedicine is a potential step to enhance health equality of Indonesian society. Therefore, this article will research telemedicine in the international law, its protection model for telemedicine patients, and the concept of telemedicine in Indonesia.

\section{Methods}

This research is a normative research with a purpose to find facts, continued with problem identification, and problem solution. Source of data used in this research is secondary data consisting of primary, secondary, and tertiary law data. The data collecting method is a noninteractive method through content analysis. Data analysis will eventually be network analysis which maps frames of individuals, organizations, situations and places.

\section{Results and Discussion}

\subsection{What is the Telemedicine?}

Telemedicine is a form of remote medical services with the use of information and communication technology with the aim of advancing the level of individual health or the general public. The components of telemedicine technology consist of a doctor, a patient, an internet container or other information exchange tool, and a health practitioner. In practice, there are 4 main fields for conducting telemedicine services, namely:

1. Teleradiology.

Teleradiology uses telemedicine to send radiological images from one location to another.

2. Telepathology

Telepathology uses telemedicine to send pathological digital to gain the image interpretation and/or consultation from it.

3. Tele dermatology

Tele dermatology uses telemedicine to send medical information regarding to skin condition for interpretation and/or consultation.

4. Telepsychiatry

Telepsychiatry uses telemedicine for evaluation session and/or psychiatric consultation through a video or voice. 


\subsection{How does it occur?}

Telemedicine facilitates the provision of medical aid from a distance. It tends to provide effectiveness to form a simpler access and reduced cost which in years to come is targeted to the rural patients in terms of decreasing the isolation from professional health care. Telemedicine can enable ordinary doctors to perform extra-ordinary tasks:

Types of Service

According to the American Telemedicine Association, telemedicine services are divided to five types:

1. Specialist required services. This kind of service usually requires the help of a specialist which also includes a practitioner whenever they decide a diagnosis. The telemedicine aspect happen when the patient consults through live call, transmission of diagnostic images, and videos of the patient data.

2. Direct patient attendance. This type of service is intervened by an audio or video in the process of medical data exchange between patient and health professional.

3. Remote patient monitoring. This kind of service benefits from the use of devices that support medical data being sent to a monitoring station. For example is "home telehealth", which replaces the need for nurse visitation. This application uses telemetry devices to record blood pressure, glucose, and ECG.

4. Medical mentoring. This is an educational type of service which widen from continuing medical education credits for health professional, towards special medical seminars, and finally interaction between expert advisor and professional performing procedure.

5. Consumer's information on health and medical data. This is the type of service we use every day in terms of telemedicine. It includes the use of internet to access health information and proceed to discussion in an online forum.

\section{Delivery Mechanisms}

In spite of taking advantage of telemedicine services, we should be aware of ways of delivery in telemedicine which includes:

1. Networked programs: This is the most common way of delivering telemedicine, because it enables the link of tertiary care facilities such as hospitals and clinics or community health centers in rural or suburban areas. This is possible through a hub and spoke and/or an integrated networked system. In approximately 3,500 medical and healthcare institutions throughout the USA, up to 200 telemedicine networks are used.

2. Point-to-point connections: This is a more private network than the networked program because it is used by medical institutions to deliver services directly to an independent medical service that are health professionals at ambulatory sites.

3. Health provider to the home: As it is stated, this is mechanisms included primary care provider entrusted to health service in a home health treatment. Of course, this mechanism requires the patient to reach their health providers through phone for consultations. This type can easily be enhanced to an extension including a residential care center.

4. Direct patient to monitoring center: This is a more specific mechanism, where it is used in particular health equipment such as a pacemaker, cardiac, pulmonary, or fetal monitoring. These equipment's have the ability to maintain independent lifestyle, which patient could easily learn how to use it by reaching a direct monitoring center. 
5. Web-based e-health: Previously discussed, these are the most humble ways of the public to understand the telemedicine. These webs enable patient service sites through the internet that seeks for public or common information regarding to health and medical data.

\subsection{Telemedicine and The International Perspective \\ Telemedicine throughout the world}

Telemedicine has already been an undergoing matter in the international technology part. In this discussion, the existence of telemedicine would be expanding through the studies of telemedicine in different countries all around the world.

1. Japan

The buds of telemedicine in Japan have arrived since the 1990's. Then, telemedicine is actually represented in the form of teleradiology. The Information and communication technology, and Digital Imaging and Communications in Medicine (DICOM), has been the biggest telemedicine that occurs in Japan.

2. India

Indian Space Research Organization's (ISRO) Telemedicine stated a need of notice to areas such as Kargil and Leh in the North, Andaman, Nicobar, Lakshwadeep, Orissa, and Karnataka as these areas still struggle in health providing. However, the NorthEaster states of India including some tribal district already have their access towards health services from some major hospitals. These accesses came with medical education, village center resource and telemedicine, mobile telemedicine, telemedicine in special situations, and telemedicine during tsunami.

3. New Zealand

Practice of medicine in New Zealand is regulated in three main ways: (1) the Health Practitioners Competence Assurance Act 2003 (HPCA Act), (2) the Office of the Health and Disability Commissioner (the HDC) through the Code of Patient Rights, (3) the Medicines Act 1981. These instruments are yet to be adjusted with the work of telemedicine.

\subsection{Telemedicine and the international law}

The international law instrument does not provide specific regulation regarding to the Telemedicine. However, there are few regulations that implicitly described the idea of this type of medical service.

1. The Ottawa Charter on Health Promotion

The Ottawa Charter is a continuation of the Alma Atta Declaration. According to the Ottawa Charter, health promotion is a process for eligible access towards parties that are involved in improving medical facilities. Moreover, this charter focuses on providing health equality throughout the world in the year 2000 and beyond.

2. United Nations General Assembly Resolution 73/91

This resolution consists of report of the Working Group on Space and Global Health by Committee on the Peaceful Use of Outer Space, decisions, and recommendation. Telemedicine is mentioned as one of the strategy to enhance health through use of outer space.

3. WHO e-Health Strategy

Since the year of 1997, the World Health Organizations (WHO) has planned health and medical service with a usage of technology and information. The fifty-eighth World Health Assembly in May 2005 adopted resolution WHA58.28 establishing an 
e-Health strategy for WHO. It calls on governments to form national e-Health bodies to provide guidance in policy and strategy, data security, legal and ethical issues, interoperability, cultural and linguistic issues, infrastructure, funding, as well as monitoring and evaluation. WHO recommends that Member States establish a national-level body for e-Health, supported by the ministry of health, as an instrument for implementing the WHA e-Health resolutions.

4. European Union (EU) Directive no. 2011/24

This Directive approves all form of health support and respects the choices of each state in their medical facilities.

5. ASEAN Telemedicine Protocol and Standard Harmonization

The ASEAN Telemedicine Protocol and Standards Harmonization purpose is to ensure knowledge promotions which consist of best practice, standards, and challenges to apply telemedicine among states. This protocol is a part of ASEAN Economic Community 2025. However it focuses on the technology and economic perspective.

\subsection{Telemedicine's Patients and Their Protection: What Does the International Law Offer?}

After going through the discussions above, the protection for telemedicine's patient in the future is through a great coordination between the international law and the national law. Below is an idea of a protection model towards patients of telemedicine:

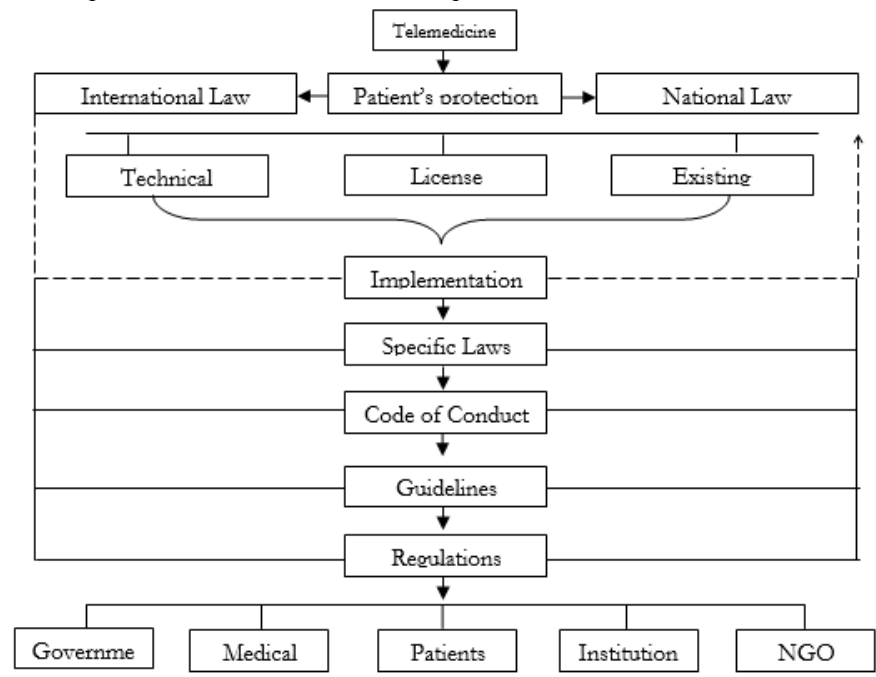

Fig 1. Model Protection for Telemedicine's Patients

This model is a developed and inspired version from Zlatko Stapić, Neven Vrček, Goran Hajdin's article in title of "Legislative Framework for Telemedicine". From the model above, it can be seen that both the international law and the national law must fulfill three elements that are basics for the telemedicine framework legislation. Those elements are technical standards, license, and existing fundamental. Through implementation, the national law will produce law products such as specific laws, code of conduct, guidelines, and regulations. In order to have these protection succeed, the parties (government, medical professions, patients, institutions, and NGO) must ensure the effectiveness of each regulations. 


\subsection{Telemedicine in Indonesia}

In Indonesia alone, the technology of telemedicine is developing even though still limited in certain aspects. It is an increase of awareness to evolve this technology to the needs and priority of patients. Indonesia is an archipelago state, thus telemedicine would be very helpful to solve the distance problem. There are several opinions that stated Indonesia ready for such technology based on wide connections. The technology information infrastructure that has connected all of the cities through Indonesia with a wide net system of Broadband, the human resources that is more than enough with skills in the technology field, and the computer software which is a product built by professionals and developed in a long time. It is a crucial part to make the sufficiency of telemedicine. To embrace the concept of telemedicine, the obstacles and Indonesia's national regulations regarding to telemedicine are two things that we must pay attention to.

\section{Urgency to implement from the International Law}

If the international community were to have an instrument specifically highlighting the medical aspect, Indonesia should be the one to implement it. The reason is that Indonesia needs a guidance and role model to actually arrange a telemedicine service. The second is to abolish the possibility of "the void of law". The third is to enable telemedicine performance in the international platform with standards and indicators to support the vision.

\section{Obstacles in adjusting the telemedicine}

The implementation of telemedicine in Indonesia until now is still developing, because through the process, there are some obstacles that is making it quite a challenge, the obstacles are:

1. Information and communication technology equipment's for medical services are below the qualified quality.

2. Purchasing the needed equipment's and hardware cost high expenses.

3. Lack of general practitioners because health practitioners in Indonesia prefer to be specialists which are unable to serve the society in rural areas.

4. Health practitioners are forced to serve more than their capability, especially in isolated places.

5. Adjustment to the diverse results of telemedicine.

\section{Indonesia's Regulations Regarding to Telemedicine}

In order of implementing the telemedicine, Indonesia has its national regulation which consists of:

1. Government Regulation No. 10 year 1966 on the obligation of medical data confidentiality

This regulation has given the society to have their rights of medical care with safety guarantees. Patients are possible to explain their complaints that are considered bothering them, either physically or psychology, with the motivation of those rights are to ensure their cure. They are hoped to not feel insecure about the privacy of their circumstances, which is not allowed to be violated by doctors or other medical staff. This is the main qualification to a good connection between doctors and patients.

2. Law No. 29 year 2004 on the Medical Practice 
The aim of this regulation is to fulfill protection to the patient, to preserve the medical service quality, and certainty of law to the society, doctors, and dentists.

3. Law No. 11 Year 2008 on the Information and Electronic Transactions

The usage of technology, information, and electronic transactions are with the aim of enlightening the society as a part of world information, to expand the national economic and trading, increasing the public service sufficiency, to share a wider vision of the usage of technology.

4. Ministry of Health Decree No. 269 year 2008 on the Medical Record

This regulation controls the privacy information to be accessed in certain benefits such as the patient's health, law enforcement request, has permissions from patient, and for the usage of education, research, and medical audit.

5. Ministry of Health Decree No. HK.02.2/MENKES/409/2016 on the Hospital Trial for Telemedicine Service Program based on Video Conference and Tele-Radiology This regulation consists of supporting hospitals and supported hospitals. Supporting hospitals task include providing recommendation services adjusting to telemedicine based on video-conference needs, providing expertise radiology services, and establishing a telemedicine service functional team. The supported hospitals shall fulfill tasks of providing medical records, informed consent, and facilitations that supports the telemedicine performance.

6. Action Plan of the Ministry of Health's Secretariat of Director General of Health Service 2015-2019

In order to enhance the Primary Level of Health Facility, this Action Plan established a policy direction. The third point of the policy is to realize service innovation which includes flying health care, telemedicine, and superior hospitals.

\section{Conclusion and Recommendation}

The international law has not regulated the telemedicine specifically yet rather subtle in the Ottawa Charter on Health Promotion, UN General Assembly Resolution 73/91, EU Directive 2011/24, and ASEAN Telemedicine Protocol and Standard Harmonization. For (international) patients of telemedicine, their protection depends on the cooperation between the international law and national law, reconsidering three basics which are technical standards, licenses, and existing fundamental law.

In Indonesia, the Ministry of Health Decree No. HK.02.2/MENKES/409/2016 on the Hospital Trial for Telemedicine Service Program based on Video Conference and TeleRadiology and Action Plan of the Ministry of Health's Secretariat of Director General of Health Service 2015-2019 have impacted the telemedicine's performance. Despite the adjustment, Indonesia has come a lot in embracing the concept of telemedicine. Through this research, recommendations are aimed to:

1. The international community is ought to form an international regulation specifically on the telemedicine, highlighting the protection for all parties involved and focusing on the health/medical perspective.

2. The Government of Indonesia must establish a policy that differs between technology, medical, and telemedicine. 


\section{References}

[1] Ahmadi, R. (2014). Metode Penelitian Kualitatif. Yogyakarta: Ar-Ruzz Media

Hasegawa T. (2013). "The Biggest Telemedicine of Japan", in the Telemedicine in Japan, Takasaki: Japanese Telemedicine And Telecare Association.

[2] Indian Space Research Organisation (2005).Telemedicine Healing Touch through Space. Bangalore: Isro Headquarter.

[3] Joko, B.T. (2016). Manfaat Telemedicine Bagi Masyarakat. Yogyakarta: Mercu Buana University.

[4] Nugrahani, F. (2014). Metode Penelitian Kualitatif: dalam Penelitian Pendidikan Bahasa. Sukaharja: LPPM Universitas Veteran Bangun Nusantara.

[5] Reponen, J. (2010). Teleradiology-Changing Radiological Service Processes From local to Regional. International And Mobile Environment. Tampere: Juvenes Print.

[6] Soekanto, S. (2012a). Pengantar Penelitian Hukum, Jakarta: Penerbit Universitas Indonesia.

[7] Soekanto, S. (2012b). Penelitian Hukum Normatif. Jakarta: PT Rajagrafindo Persada.

[8] Arisandy, W. Strategi Dinas Kesehatan dalam Meningkatkan Kualitas Pelayanan Kesehatan Melalui Metode CRC (Citizen Report Card)" di Kota Surabaya. Kebijakan dan Manajemen Publik, Vol. 3(2), pp. 13.

[9] British Association of Dermatologists. (2010). The Role of Teledermatology in the Delivery of Dermatology Services, pp. 1.

[10][ CIMB Research Institute. (2018). AEC Blueprint Analysis 2025: An Analysis of the ASEAN Cooperation in Information and Communications Technology (ICT)", Vol.1(3), pp. 4.

[11] Daley, H.A. (1995). Telemedicine: The Invisible Legal Barriers to the Health Care of the Future. Annals of Health Law, Vol. 9(1), pp. 75.

[12] Erikkson, M. and Bengt Lingström. (2008). A Salutogenic Interpretation of the Ottawa Charter,. Health Promotion International, Vol. 23(2), pp.190.

[13] Hedley, H. (2015). Telemedicine in NZ and Across Borders-the Legal Challenges, (2015), 1.

[14] Hilty, D. M. (2004). Clinical and Educational Telepsychiatry Applications: A Review. The Canadian Journal Of Psychiatry, Vol. 49 (1), pp. 14.

[15] Melamed, Barbara. (2004) Technology and Medical Advances: Implications For Health Psychology. The American Psychology Association, Vol. 23(2), pp. 143.

[16] Siegel, G. (2017). New Technologies: Real-Time Telepathology Systems-Novel Cost-Effective Tools For Real-Time Consultation And Data Sharing. Toxilogic Pathology, Vol. 45(8), pp. 1039.

[17] Stapic, Z. (2008). Legislative Framework For Telemedicine. University of Zagleb, pp. 5. World Trade Organization. (2010). "Telemedicine: Opportunities and Developments in Member States", Global Observatory for Ehealth Series, Vol. 2, pp. 82.

[18] "Telemedicine, Telehealth, and Health Information Technology", The American Telemedicine Associaton. Accessed June, 2019, www.americantelemed.org/home.

[19] "The Ottawa Charter For Health Promotion,", World Health Organization, accessed July, 2019, https://www.who.int/healthpromotion/conferences/previous/ottawa/en/

[20] Telemedicine in Indonesia "Countries Experiences", World Health Organization accessed July, 2019, http://www.who.int/countries/id/en/. 